\title{
Beehive Dispersion in Sachet
}

National Cancer Institute

\section{Source}

National Cancer Institute. Beehive Dispersion in Sachet. NCI Thesaurus. Code C149356.

Medicinal product consisting of a bee-hive dispersion presented in a sachet. 